This item was submitted to Loughborough's Research Repository by the author.

Items in Figshare are protected by copyright, with all rights reserved, unless otherwise indicated.

\title{
Political talk on mobile instant messaging services: a comparative analysis of Germany, Italy, and the UK
}

PLEASE CITE THE PUBLISHED VERSION

https://doi.org/10.1080/1369118X.2017.1350730

\section{PUBLISHER}

(C) Taylor \& Francis

\section{VERSION}

AM (Accepted Manuscript)

\section{PUBLISHER STATEMENT}

This work is made available according to the conditions of the Creative Commons Attribution-NonCommercialNoDerivatives 4.0 International (CC BY-NC-ND 4.0) licence. Full details of this licence are available at: https://creativecommons.org/licenses/by-nc-nd/4.0/

\section{LICENCE}

CC BY-NC-ND 4.0

\section{REPOSITORY RECORD}

Valeriani, Augusto, and Cristian Vaccari. 2017. "Political Talk on Mobile Instant Messaging Services: A Comparative Analysis of Germany, Italy, and the UK". Loughborough University.

https://hdl.handle.net/2134/28251. 
Political Talk on Mobile Instant Messaging Services:

A Comparative Analysis of Germany, Italy, and the United Kingdom

\author{
Augusto Valeriani (corresponding author) \\ University of Bologna \\ Department of Political and Social Sciences \\ Strada Maggiore, 45 \\ 40125, Bologna (IT)
}

mail to: augusto.valeriani@unibo.it

Cristian Vaccari

Royal Holloway, University of London and University of Bologna 


\begin{abstract}
:
Mobile instant messaging services (MIMS) are emerging as important digital environments in citizens' everyday lives. We explore the use of MIMS for talking about politics with unique survey data on samples representative of internet users in Germany, Italy, and the United Kingdom. First, we show that robust percentages of our respondents who use MIMS employ them for posting political messages and discussing politics. Secondly, we demonstrate that political talk on MIMS is positively associated with users' tendency to censor themselves politically on social networking sites (SNS) and, to a lesser extent, with ideological extremism. Thirdly, we find that the association between self-censorship on SNS and the likelihood of publishing political contents on MIMS is stronger for individuals living in former East Germany where, due to historical reasons, large segments of the population are reluctant to talk about politics in public. Our findings suggest that MIMS make a distinctive contribution to contemporary repertoires of political talk, with important implications for the quality and inclusiveness of interpersonal political discussion.
\end{abstract}

Keywords: Mobile Instant Messaging Services, social media, political discussion, comparative research

Word count: 7,999 (including tables) 


\section{Introduction}

Mobile instant messaging services (MIMS) such as WhatsApp, Facebook Messenger, and Snapchat ${ }^{1}$ are applications that allow individuals and groups to exchange text and multimedia messages via their mobile devices. These platforms are challenging, and in some countries surpassing, social networking sites (SNS) as the most adopted digital means for social connection. WhatsApp, the most popular of these services globally, was reported to have a billion users worldwide in February 2016, being outnumbered only by Facebook. ${ }^{2}$

MIMS are mobile native applications, developed and conceived for smartphones. Therefore, their adoption is connected to the evolution of mobile communication devices and the use of the internet in mobility. This is important because, as argued by Campbell (2013), "mobility matters" in shaping the social implications of communication technologies. By enabling information flows that are unbounded from physical barriers while intertwined with users' daily routines, mobile communication disrupts "users' connection to spaces and co-present others, while also serving as a new way to interface with locations as hubs of social activity" (Campbell 2013, p. 11).

Research has addressed how these features of mobile communication can impact political information and participation (Neumayer \& Stald, 2014) and the profiles of citizens engaged in such activities (Martin, 2015). However, scholars have by and large overlooked the differences between the various technologies through which individuals

\footnotetext{
${ }^{1}$ Snapchat is technically a MIMS since it allows users to share videos and chat with their contacts via mobile devices. However, it can be argued that some of its affordances make it similar to a social networking platform: "Stories" can be publicly shared and the "Discover" section contains "dedicated channels" curated by major publishers and news organizations. However, even fragments of public stories can be commented only privately and nobody is allowed to know who is connected to a user. These features make the service closer to MIMS than to SNS, at least for the purposes of the present study. ${ }^{2}$ See http://www.wired.com/2016/04/forget-apple-vs-fbi-whatsapp-just-switched-encryption-billionpeople/ (accessed 18 May 2016).
} 
can engage with mobile political communication, and the different affordances these technologies entail. Text-messaging, emails, web browsing, mobile applications of news organizations, SNS, and MIMS all enable users to access and share political information on the move, but do so in markedly different ways, appealing to different types of users. Therefore, the impact of MIMS on political discussion should be assessed not only as part of the broader phenomenon of mobile communication, but in light of the specific features of these platforms. Importantly for political talk, MIMS enable conversations in relatively more intimate, closed, and controlled environments than SNS.

We shed light on the role of MIMS in contemporary citizens' political talk by presenting unique online survey data based on samples representative of internet users in Germany, Italy, and the United Kingdom. The data show that robust percentages of our respondents who use MIMS employ them for publishing political messages and discussing political matters. Multivariate analyses demonstrate that users who tend to censor their own political opinions on social media and those holding extreme ideological positions are more likely to engage in political talk on MIMS. Our comparative design then helps us uncover that the association between self-censorship on SNS and posting political messages on MIMS is stronger for individuals living in former German Democratic Republic (East Germany) than former Federal Republic of Germany (West Germany). In East Germany, the communist regime which was in power before the 1989 reunification established a highly pervasive surveillance system — the infamous State Security Service (STASI). One of its lasting legacies is widespread discomfort with political expression within public environments among former East German residents-which helps explain why, even to this day, those of them who are less than confident in expressing their views in relatively public social media are more comfortable speaking out on MIMS. 
Taken together, our findings suggest that MIMS play a distinctive role in contemporary ecosystems enabling political talk. MIMS appeal to citizens who especially value the intimate nature of these services, whether because of their self-consciousness in expressing some of their political views on more open digital spaces or because they hold more extreme political views. Our comparative analysis shows that these patterns can be reinforced by political culture.

\section{Literature Review and Hypotheses}

\section{The Craft of the Networked Self between Open and Closed Digital Spaces}

Rainie and Wellman (2012) argued that "networked individualists"—i.e., individuals connected with others through multiple and diverse networks—should be considered the key actors of contemporary "social operating systems". On the one hand, digital platforms complicate strategies of self-presentation because they frequently "combine a variety of audiences, of variable privacy and publicity into a single crowd of spectators observing the same performance" (Papacharissi, 2011, p. 307). On the other hand, networked individualists can take advantage of this conflation by establishing multiple connections well beyond the "little boxes" (Wellman, 2002)—the smaller and more clearly defined groups where most social life was previously performed. However, they must also carefully manage their "networked self" to simultaneously cope with the expectations of the multiple audiences they can reach via digital networks (Papacharissi, 2011).

Individuals connecting with one another in online environments coalesce in "networked publics", which boyd (2011, p. 49) defines as characterized by three 
features: invisible audiences, as members do not have extensive information on who may be exposed to their communication; collapsed contexts, as digital networks often traverse established social boundaries; and the blurring of public and private dimensions of the self. These phenomena have relevant implications for political talk (Papacharissi, 2015). Citizens who talk about politics in digital environments interact with audiences and in situations that may be more difficult to define, understand, and control than in face to face settings.

The diffusion of mobile technology has been credited as one of the factors contributing to the development of networked individualism (Rainie \& Wellman, 2012). However, the specific affordances of different types of platforms used through mobile devices could have different implications for how networked individuals engage in political talk while on the go. The concept of "intermediality", or the simultaneous availability of different modes of communication (Helles, 2013), is relevant here. Mobile devices such as smartphones and tablets enable users to craft their own experiences by mixing various applications according to their needs, interests, and goals (Goggin, 2009). Therefore, in studying political talk on MIMS, we must start by analyzing the peculiarities of these services vis a vis SNS as well as traditional short text messages.

First, MIMS are mobile native and are accessible exclusively—or nearly so ${ }^{3}$ —via mobile devices. By contrast, mobile users access SNS via Apps that are mobile versions of the services available via desktop and laptop computers. Some studies have addressed how users assess the differences between MIMS and other mobile channels for social connectivity. Church and De Oliveira (2013) showed that users perceive

\footnotetext{
${ }^{3}$ Some services can also be accessed via desktop or laptop computers, but only through relatively cumbersome procedures, i.e. employing emulators of mobile operating systems or-only for WhatsAppsyncing a mobile device with a computer. Facebook Messenger is an exception, since it is by default synced with the private messaging function of Facebook, but the user interfaces for the mobile and computer versions differ substantially.
} 
WhatsApp as more immediate and conversational, and thus conducive to more natural social interactions, than traditional short text messages. O'Hara, Massimi, Harper, Rubens, and Morris (2014) revealed that users favor WhatsApp to maintain intimate relationships with people they consider emotionally close and are, often, geographically proximate. They argued that discussion threads on WhatsApp "were viewed by participants as something that would be picked up again whenever and wherever. Just as the friendship is never ending, so the thread of encounters is in WhatsApp" (p. 6). Finally, Utz, Muscanell, and Khalid found that users took advantage of the "private nature" of Snapchat to build smaller and tighter networks than on Facebook, valuing Snapchat as an alternative to the public and one-to-many setting of communication characterizing most SNS (2015, p. 144; see also Vaterlaus, Barnett, Roche, \& Young, 2016).

This is not to suggest that users connect exclusively with strangers on social networking websites, and exclusively with close acquaintances on MIMS. To the contrary, maintaining relations with family, friends, acquaintances and offline contacts in general represents a highly relevant function of social media (Ellison, Steinfield, \& Lampe, 2007). However, the affordances of most SNS favor the integration of strong and week ties (Ellison et al., 2011) and users of these platforms are encouraged by their affordances to broadcast their messages to their whole, relatively broad networks, as well as being exposed to broadcasts from others they are connected to. The degree to which users experience a platform as a public or private space also results from the interplay between its affordances and the communities inhabiting it. The massive diffusion of Facebook, which makes it a highly crowded space, encourages users to experience it as a public or semi-public environment (boyd 2014, pp. 204-205). Therefore, the collapse of contexts and the consequent necessity of performing the self 
in front of multiple, and partially invisible, audiences are particularly intense on SNS, especially the most popular ones (Marwick \& boyd, 2011).

By contrast, MIMS users interact with individual contacts or clearly defined groups and can check whether their messages have been seen and by whom thanks to read receipts. On some MIMS, such as Snapchat, users can even limit the time their message is visible for its addressees (Clark 2016, p. 238). While MIMS retain some relevant digital features that contributed to the development of networked individualism—such as the emergence of different "social clusters" crafted around individuals (Song, 2010, p. 267) — they also enable users to recreate Wellman's (2002) "little boxes", where people engage with small groups and individual users. In boyd's (2011) terminology, context collapse is less likely to occur on MIMS than on SNS, audiences on MIMS are less invisible to users than those on SNS, and the prevalent mode of communication on MIMS is more likely to tilt towards the private than the public when compared to SNS.

In this paper, we assess how these properties of MIMS may enable different forms of political talk. We theorize that certain types of individuals are particularly likely to turn to MIMS for political talk because they provide more intimate, closed, and controlled environments than the more open and public SNS. We argue that the affordances highlighted above should make MIMS particularly appealing for individuals who are reluctant to express themselves politically in more public digital spaces, and for individuals whose political ideology is relatively extreme-and thus more likely to elicit opposition if voiced in open environments and broader networks. 
According to the Uses and Gratification theory (Katz, Blumler, \& Gurevitch, 1973), individuals choose and exploit the specific features of different media to gratify particular needs and goals. Originally developed for the mass media, this theory has been employed more recently to explain different uses of digital media (e.g. Cho, Gil De Zúñiga, Rojas, \& Shah, 2003; Quan-Haase \& Young, 2010).

Most citizens are reluctant to talk about politics in public settings (Schudson, 1997; Eliasoph, 1998), especially when discussion revolves around divisive issues or when they fear most participants disagree with them (Noelle-Neumann 1974). For the reasons highlighted above, social networking sites only partially shelter reluctant political talkers from these concerns. Those individuals may be more at ease talking about politics in spaces that are more private, closed and intimate-such as those enabled by MIMS. Although social media users tend to cluster and select content according to their political preferences (Gaines \& Mondak, 2009; Bakshy et al. 2015), experience of political disagreement on SNS is not uncommon (Vaccari et al., 2016), potentially making political talk on social media an uncomfortable experience. This could be especially true for people who are particularly concerned that expressing their views on controversial issues in the broadcast mode encouraged by SNS may damage their relationships with some members of their wide networks. Rather than face those risks, these people could then decide to withhold their political opinions, as occurs in face-to-face settings (Hayes, Glynn, \& Shanahan, 2005). Das and Kramer (2013) observed the behavior of 3.9 million Facebook users for 17 days and concluded that "last-minute self-censorship" (i.e. eventually deciding not to publish a post or comment after having typed it) is quite common: $71 \%$ of monitored users censored at least one of their posts or comments (on any topic) in this way. Sleeper et al. (2013) found that one of the main motivations why Facebook users censor themselves was that they fear their 
posts may reach beyond their intended audiences. Although Facebook enables users to determine which subgroups within their networks can see their posts, participants found those features "confusing or difficult to use" (p. 8), resorting to self-censorship as a safer option instead.

Based on the Uses and Gratifications theory and the empirical evidence on selfcensorship on social media, we expect that users who censor themselves politically on SNS should be more likely to use MIMS for political talk, as they may feel more at ease in expressing and exchanging political views within the tighter networks and private environments that characterize these platforms. We thus hypothesize that individuals' propensity towards political self-censorship on Social Networking Sites is positively associated with their likelihood to employ Mobile Instant Messaging Services for political talk (H1).

Using MIMS for political talk could also be gratifying for citizens holding relatively extreme ideological positions. Ideologically extreme views appeal to minorities of the population and are frequently stigmatized in democracies, especially those characterized by problematic authoritarian legacies and centripetal party competition. Extremists are therefore less likely to openly express their views in public (Noelle-Neumann, 1984). These elements might lead citizens who place themselves at the extremes of the ideological spectrum to prefer intimate and closed environments for political talk. Accordingly, research suggests that political extremists use the internet not to communicate with the general population, but to create networks of websites, blogs, forums and bulletin boards where they can establish more intimate connections with likeminded people, thus generating alternative spheres for political talk (e.g. Caiani \& Wagemann, 2009; Wojcieszak, 2010). 
Individuals holding extreme political views may therefore see MIMS as a particularly comfortable environment for political talk. The high level of network selection and message control allowed by these platforms facilitates the circulation of controversial information and opinions within closed circles, where individuals face lower risks of incurring sanctions from opponents. Moreover, extreme views can be banned on other digital arenas: for instance, Facebook can remove content and close pages that host hate speech. ${ }^{4}$ We therefore hypothesize that individuals with relatively more extreme ideologies are more likely to employ Mobile Instant Messaging Services for political talk (H2).

\section{Political Self-Censorship in Context}

In reassessing the "Spiral of Silence" theory (Noelle-Neumann, 1974), Scheufele and Moy (2000) argued that scholars wishing to understand how individuals decide to express or withhold their opinions in public in the face of widespread dissent should pay more attention to the role of cultural characteristics. We build on this insight and leverage our comparative research design to explore how the legacy of intrusive government surveillance impacts present-day citizens' political culture, and in particular their confidence to talk about politics in public and private digital spaces (MacKinnon, 2011).

To assess the role of these aspects of political culture, we compare three established European democracies: Germany, Italy, and the United Kingdom, focusing in particular on differences between former East and West Germany. Historically, East Germany was characterized by a highly pervasive state surveillance, established by the

\footnotetext{
${ }^{4}$ See https://www.facebook.com/communitystandards (accessed 8 December 2016)
} 
communist regime that ruled the country (1949-1990) before Germany was reunified. State surveillance in East Germany strictly monitored all aspects of citizens' social lives based on extensive networks of informants. Authorities routinely demanded the population report "suspect" fellow citizens (Betts, 2010). This context fostered a culture of deeply ingrained distrust and suspicion for others, eroding social capital and impacting several aspects of public life (Jacob \& Tyrell, 2010).

Such traumatic heritage is likely to have lasting impacts on the political culture of citizens who experienced it and on their first offspring, and in turn may affect their approach to political talk in different online platforms. The legacy of state surveillance may discourage some East Germans from exchanging political views on relatively more open digital platforms, while increasing the appeal, among those politically selfconscious users, of more closed online environments. To test this theory, we need to ensure that the relationships of interest are not confounded by other systemic factors that differ across the countries included in our study. Therefore, we compare citizens of the former East and West Germany, as the latter, while living today in the same country as the former, did not experience a similar surveillance regime in the recent past, and their offspring's political socialization was not affected by memories of such invasive state monitoring. We thus hypothesize that the association between individuals' tendency towards political self-censorship on SNS and their likelihood to employ MIMS for political talk is stronger for citizens living in the former East Germany than for those living in the former West Germany (H3).

Besides Germany, this study also covers Italy and the United Kingdom. Albeit similar in many ways, such as being large and relatively affluent European democracies, these countries differ from one another in various important aspects. The diffusion of 
digital platforms is of relevance here. According to commercial data from January $2016^{5}$, SNS are used by $59 \%$ of British citizens, $47 \%$ of Italians, and $36 \%$ of Germans. When it comes to MIMS, in Germany WhatsApp—the most popular MIMS there-has overtaken Facebook in term of users (39\% vs. 38\% among internet users) and in Italy it is close to the same landmark (33\% for Facebook vs. 30\% for WhatsApp), while in the UK Facebook is still firmly leading (47\% vs. $24 \%){ }^{6}$ It is also worth noting that, while no national elections were held in Germany and Italy in 2015-the year when we collected our data-a general election had been held in the UK six months before our surveys were fielded. These differences, which will be taken into account in analyzing our findings, will enable us to establish more robust generalizations than if we had studied a single country.

\section{Data, Variables, and Models}

\section{Data}

We test our theories with custom-built Computer-Assisted Web Interviewing (CAWI) surveys conducted in Germany, Italy, and the United Kingdom. Surveys were administered by IPSOS and responses were collected between November 10-December 1,2015 . For each country, a sample $(N=1,750)$ of Internet users aged $18-74$ years was constructed with quota sampling to ensure that the survey population would be representative of the adult population with internet access in each country. The variables included in the quota sampling were age, gender, region of residence (based

\footnotetext{
${ }^{5}$ See http://wearesocial.com/special-reports/digital-in-2016 (accessed 22 May 2016).

${ }^{6}$ See Note 5.
} 
on NUTS27 classification), occupational condition, and educational level. Respondents were recruited from online panels and were offered non-monetary incentives to participate. Participation rates were $20.2 \%$ for Germany, $20.5 \%$ for Italy, and $19.1 \%$ for the United Kingdom. ${ }^{8}$

\section{Variables and Models}

Our hypotheses focus on the factors predicting the likelihood of using MIMS for political talk. We operationalize two different dimensions of political talk: one-way talk, i.e. sharing political messages, and two-way talk, i.e. discussing political issues with others. This distinction enables us to account for different behaviors that, while overlapping to some extent, do not necessarily coexist all the time. The questions measuring these dependent variables were included in a battery introduced as follows: "Over the past 6 months, when using these instant messaging services [previously specified as 'WhatsApp, Facebook messenger, Viber, WeChat, Snapchat, and the like'], have you...?' The two items were: "sent messages about politics or public affairs" and "discussed politics or public affairs". Response modes were "Yes", “No", and "Don't know" (treated as missing value). These questions were asked only to respondents who previously reported using MIMS.

\footnotetext{
${ }^{7}$ NUTS stands for "Nomenclature of Territorial Units for Statistics" and is a geographical classification that subdivides territories of the European Union into regions at three different levels. See http://ec.europa.eu/eurostat/web/nuts/overview (accessed June 2016).

8 9,021 invitations were sent in Germany, 9,000 in Italy, and 9,500 in the United Kingdom. In Germany, 6,660 recipients did not open the survey link, 247 abandoned the interview and 364 were screened out or turned out to be over quota. In Italy, 6,493 recipients did not open the survey link, 304 abandoned the interview and 453 were screened out or turned out to be over quota. In the United Kingdom, 7,163 recipients did not open the survey link, 260 abandoned the interview and 327 were screened out or turned out to be over quota.
} 
Our independent variables measure political self-censorship on SNS (H1 and H3) and ideological extremism (H2).

We measure political-self censorship on SNS trough the question: "In managing the personal relationships on social networks / social media platforms (Facebook, Twitter, YouTube etc.) in which you discussed politics with someone, during the last 6 months have you ... not published political content for fear of offending someone, or compromising yourself too much?". Response modes were "Yes", "No", and "Don't remember" (treated as missing value). $21 \%$ of German, $22.8 \%$ of British and $26.5 \%$ of Italian respondents who used social media reported censoring themselves in this way.

To measure ideological extremeness, we employ answers to the question: "Many people use the terms 'left' and 'right' when talking about politics. Where do you place yourself on this scale?" Respondents were asked to locate themselves on a 7-point scale. The first point on the left was labeled as "Left" (chosen by $6.6 \%$ of German, $4.3 \%$ of British and $8.1 \%$ of Italian respondents) and the last point on the right as "Right" (chosen by $2.2 \%$ of German, $5.7 \%$ of British and $11.8 \%$ of Italian respondents). Answers were recoded into a variable measuring level of political extremism, ranging from 0 (respondents describing themselves as centrist or answering that they did not identify themselves with these terms) to 3 (respondents who chose one of the two extreme points in the scale).

We conducted all analyses on a pooled dataset to better assess the significance of differences in the strength of the relationships between variables in different countries. To test H3, we clustered British and Italian respondents by country, while creating two separate clusters for those residing in regions of the former East and West Germany. ${ }^{9}$

\footnotetext{
${ }^{9}$ We classified respondents residing in Berlin as residents in former East Germany. Given the peculiar history of Berlin, we also ran our models excluding Berlin residents and the results were consistent with
} 
We then created an interaction term between political self-censorship on SNS and residence in East Germany, with residence in West Germany as the reference category. Since our dependent variables are dichotomous, we employ logistic regressions to test our hypotheses. Our models control for gender, age, education, income, political efficacy, interest in politics, exposure to political news through different channels (television, printed newspapers, radio, and internet websites), and frequency of political discussion offline and on SNS. We also control for frequency of access to the internet via smartphones, use of smartphones to produce multimedia content, and membership in groups on MIMS. Intensive and competent uses of mobile devices, as well as the kinds of networks tapped via these tools, can affect the relationship between mobile communication and political engagement (Campbell \& Kwak, 2010).

It should be noted that our SNS-related questions were asked only to respondents who reported having a profile on at least one platform $(84.8 \%$ of German, $87.9 \%$ of British, and $95.5 \%$ of Italian respondents), while those related to MIMS were asked only to users of those services. Consequently, our findings only apply to respondents who use both SNS and MIMS. Supplementary analyses established that this choice did not introduce any substantial biases due to individuals' selecting themselves into using SNS, MIMS, or both. ${ }^{10}$

\footnotetext{
those discussed in this article. (Data available upon request.) It might be argued that the internal migration that occurred in reunified Germany since 1989 makes it problematic to employ respondents' current region of residence to test our hypothesis. However, most of this migration ran from East to West and occurred in the two years after reunification (Hunt, 2006). Therefore, our sample likely includes more West German residents formerly living in East Germany than East German residents formerly living in West Germany. To the extent that such distortion exists, it should bias our findings against rather than in favor of $\mathrm{H} 3$.

${ }^{10}$ We ran the same analyses with data including all respondents, as well as all respondents who used MIMS regardless of whether they used social media. In these models, we recoded as " 0 " those respondents who were not asked a question about political uses of SNS or MIMS because they had not reported using either or both platforms. The models based on all respondents using MIMS, irrespective of whether they used SNS or not, yielded substantively identical findings to those reported here for all three hypotheses. The models based on all respondents, irrespective of whether or not they used both MIMS and SNS, yielded substantive identical findings for $\mathrm{H} 1$ and $\mathrm{H} 3$. With respect to $\mathrm{H} 2$, the coefficients for ideological
} 


\section{Findings}

Descriptive statistics on MIMS' general and political use offer some interesting insights into the importance of these platforms for political talk. $61.9 \%$ of German respondents use MIMS, 22.1\% of those German MIMS users post political content, and 25\% discuss politics on these services; $55.4 \%$ of British respondents are active on MIMS, $38.1 \%$ of them publish political messages, and 33.5\% talk about politics there; finally, $83.3 \%$ of Italians employ MIMS, $28.4 \%$ of them send politics-related posts, and $27.8 \%$ engage in political conversations therein. These statistics show that, although the diffusion of MIMS varies substantially across the three countries, political talk is more evenly distributed, especially in its two-way dimension. Moreover, MIMS users are more likely to engage in both one-sided and two-sided political talk in the UK, where these services are relatively less popular, than in Germany and Italy, where they are more popular. The fact that the United Kingdom is the only country among those considered here where a national election was held in 2015 might contribute to explaining this pattern. Although we did not ask respondents to recall behaviors that occurred during the campaign, ${ }^{11}$ British respondents may still have been influenced by the relatively recent experience of the campaign in reporting their political activities on MIMS. An alternative explanation may be that, since MIMS are less widely used in the UK than Germany and Italy, British users may exhibit some of the typical features of early adopters, and may thus use these platforms more actively.

extremism were in the same direction and had similar strengths as those reported here, but fell slightly below the conventional significance thresholds $(\mathrm{B}=.092, p=.074)$ when posting political messages on MIMS is the dependent variable. (Data available upon request.)

${ }^{11}$ Our questions referred to the six months preceding the interview, while the British general election was held more than six months before our surveys were in the field. 
Interesting patterns emerge when we compare the diffusion of political talk on MIMS and SNS. Among respondents who talk about politics on MIMS and are also SNS users, $51.1 \%$ of Germans, $51 \%$ of British and $42.7 \%$ of Italians reported sending political messages on MIMS but not publishing political content on social media. ${ }^{12}$ Similarly, $29.4 \%$ of Germans, $32.9 \%$ of British, and $33.8 \%$ of Italians who discussed politics on MIMS did not do so on social media even though they are users of those platforms. These data show that political talk on MIMS and SNS overlap to some extent, but quite a few respondents (one in two in Germany and the UK when it comes to political posting, one in three in Italy with respect to discussing politics) who use both platforms talk about politics on MIMS but not on SNS. These findings suggest that MIMS play a specific role vis-à-vis SNS as channels for online political talk.

We now address our hypotheses, which we tested through logistic regressions (Table 1 and Table 2) predicting whether respondents report posting political messages and engaging in political discussions on MIMS.

[Table 1]

The coefficients for self-censorship on SNS are positive and significant in both models, supporting the hypothesis that political self-censorship on social networking sites is positively associated with employing MIMS for political talk (H1). Even after controlling for all the other variables in the model-including, crucially, frequency of political talk in both SNS and face-to-face contexts-respondents who censor

\footnotetext{
12 Our battery on political activities on SNS did not feature a question identical to the one measuring political posting on MIMS. Here, we refer to answers to the item "...published political news or comments" (on SNS). This comparison is acceptable since political news and comments are indeed messages about politics and public affairs.
} 
themselves politically on social media are more likely to publish political messages and to engage in political discussions on MIMS. This finding suggests that MIMS are a viable arena for political talk among people who are not completely confident in expressing all their opinions on SNS. If we construct a hypothetical respondent for whom all variables have values equal to the mean in our sample (calculated based on respondents included in the multivariate analysis), the probability that this hypothetical respondent discuss politics on MIMS is predicted to jump from $22 \%$ if she did not censor her political views on SNS to $34 \%$ if she did.

Table 1 also provides partial support for our hypothesis that ideological extremism is positively associated with the use of MIMS for political talk (H2). The coefficient of the variable measuring extremism is positive in both models, and significant in the model predicting the likelihood of posting political messages on MIMS. While a hypothetical average respondent who describes herself as centrist (or refuses to locate herself in the left-right scale) has a $23 \%$ probability of publishing political messages on MIMS, that probability grows to $30 \%$ for a similar respondent who places herself at one of the extremes of the scale. However, we did not find any significant association between ideological extremism and political discussion on MIMS, so H2 is supported only with respect to one-way political talk.

Table 1 also reveals different types of inequalities driving political talk on MIMS. There are positive and significant associations between both one-way and two-way political talk on MIMS and political discussion occurring both offline and on SNS. This suggests that habitual political talkers use MIMS to supplement rather than replace their conversations in other digital and physical spaces. Mobile-only applications can offer frequent political talkers new opportunities to gratify specific needs-for instance, posting political messages while on the move or talking about politics within closed 
groups of "political junkies". They also support a "rich get richer" vision of digital politics, consistent with the fact that political efficacy and access to political information are positively and significantly associated with both posting and discussing politics on MIMS. Furthermore, the positive and significant association between creative use of smartphones and both one-way and two-way political talk highlights the "democratic divide" resulting from inequalities in digital skills (Min, 2010).

Other findings, however, suggest that political talk on MIMS is not solely the purview of politically active citizens (Martin, 2015). Age and education are negatively associated with both one-way (only the former significantly) and two-way (both significantly) political talk on MIMS, and the coefficients for interest in politics, while positive, are not significant. Importantly, both one-way and two-way political talk on MIMS were positively and significantly associated with membership in groups on these platforms. This indicates that MIMS' potential to promote political talk may depend in part on how their affordances enable users to build and engage with different networks, aside from one-on-one interactions. These groups may often be non-political in scope, but may result in occasional, even accidental, political exchanges that reach beyond the types of citizens who normally discuss politics.

We now assess how context shapes political talk on MIMS. We hypothesized that the association between political self-censorship on SNS and the likelihood of employing MIMS for political talk is stronger among residents in former East than West Germany (H3). We test this hypothesis by adding to our initial models an interaction term between self-censorship on SNS and the variables clustering our respondents residing in the UK, Italy, and former East Germany, with residents in West Germany serving as reference category. 
[Table 2]

The results in Table 2 provide some support to $\mathrm{H} 3$, as the coefficient for the interaction term between self-censorship on SNS and residence in former East Germany is positive and significant in the model predicting one-way political talk. The coefficient is also positive and close to the conventional threshold for statistical significance ( $p=$ .057) in the model predicting two-way political talk. Thus, all else being equal, the association between self-censorship on social media and political posting on MIMS is stronger for Germans residing in former East than West Germany. The coefficients for the interaction terms involving British and Italian respondents are quite similar to each other, and far from statistical significance. Thus, there are no discernible differences between how political self-censorship on SNS is associated with political talk on MIMS among British, Italian, and West German respondents. This increases our confidence that the patterns we have identified can be explained specifically by differences between East and West Germans' political culture.

The fact that the coefficient for the variable clustering East German residents is negative and significant suggests that East Germans who do not censor themselves politically on social media are substantially less likely to post political messages on MIMS than their West German counterparts. In other words, MIMS are not more popular among East German than West German respondents per se-they are actually less popular among East German respondents who do not censor themselves politically on SNS. However, East Germans who are concerned about expressing some of their political thoughts on SNS are noticeably more likely than West Germans of similar inclinations to rely on MIMS to post political messages. A hypothetical average West German resident who censors some of her political posts on social media has a 33\% predicted probability 
of posting political messages on MIMS. If we construct this average respondent as an East German resident, the probability soars to $56 \%$.

Some limitations of this study need to be acknowledged. First, our hypotheses are tested by employing cross-sectional data that do not allow us to empirically ascertain the causal direction of the relationships we investigated, and some endogeneity cannot thus be ruled out. Longitudinal survey data and experimental research would be better suited to study these causal mechanisms. Secondly, our sample is based on a panel administered online, albeit constructed to mirror the distribution of the main sociodemographic characteristics of the population with Internet access. Respondents recruited via online panels may be more active on the internet and on MIMS than the average internet user, and our data may therefore over-estimate the percentage of SNS and MIMS users and their levels of political talk. However, we are confident, based on several recent studies (e.g. Sanders, Clarke, Stewart, \& Whiteley, 2006; Pasek, 2016; Bytzek \& Bieber, 2016) that our samples produced correct estimates of the relationships between our variables of interest, even if they may have not yielded accurate estimates of their univariate distributions. Reliance on self-reports is also less than ideal due to the pervasiveness of MIMS in their users' everyday lives, which may bias recall of communication exchanges that are often short, fragmentary, and compete for attention with other simultaneous digital and physical stimuli. Finally, our measures refer to MIMS use in general, but citizens' uses of, and gratifications from, digital platforms derive from their specific affordances and may thus vary substantially between different mobile services. Future research may benefit from a more granular approach focused on the political uses of specific MIMS, ideally by combining quantitative and qualitative data and supplementing self-reports with unobtrusive observations of users' interactions. 


\section{Conclusions}

Mobile Instant Messaging Services are becoming relevant environments for political talk. By facilitating intimate and controlled conversations within small groups while on the go, MIMS have acquired a relevant position in the repertoires of political talk of many—though not most—of their users. This is especially true for users who are so politically self-conscious to censor some of their political thoughts when posting on social media, and for users who hold ideologically extreme positions. Such individual dispositions are compounded by systemic factors, such as historically rooted political cultures favoring privacy over openness in political talk.

These findings have ambivalent implications for the quality of political debate in contemporary media ecosystems. On the one hand, MIMS enable people who do not feel confident in broadcasting some of their political views to their whole, undifferentiated online networks to more comfortably express and discuss their positions in more closely controlled settings. This may encourage more-and more diverse-citizens to engage in political talk on MIMS, and such talk may in turn enhance MIMS users' political knowledge and engagement. On the other hand, by discussing politics in private and selective settings, MIMS users could entrap themselves in small political bubbles of likeminded strong ties, possibly holding more extreme political views than the rest of their networks. If these patterns result in a reduction of the ratio of political talk involving weak ties in favor of strong ties, they can have negative implications for informal deliberation (Campbell \& Kwak, 2010) and participation (Gil de Zúñiga and Valenzuela (2011).

The rise of MIMS as platforms for digital political talk challenges scholars to reconsider the theories and models with which we understand the social and political 
implications of information and communication technologies. MIMS seem to be augmenting but also complicating the development of networked individualism, as subjects use these platforms to craft smaller and more private social clusters alongside with-or, conceivably, in substitution of - the relatively more inclusive and open networks characterizing the most popular social networking sites as they have evolved so far. Creative theoretical reasoning and fresh empirical research are needed to understand the implications of these changes for the nature of personal communication ecosystems-including the extent to which they enable different forms of political talk. 


\section{References}

Bakshy, E., Messing, S., \& Adamic, L. A. (2015). Exposure to ideologically diverse news and opinion on Facebook. Science, 348(6239), 1130-1132.

Betts, P. (2010). Within walls: Private life in the German Democratic Republic. Oxford University Press.

Bytzek, E., \& Bieber, I. E. (2016). Does survey mode matter for studying electoral behaviour? Evidence from the 2009 German Longitudinal Election Study. Electoral Studies, 43, 41-51.

boyd, d. (2011). Social Network Sites as Networked Publics. In Z. Papacharissi (Ed.), A Networked Self. Identity, Community and Culture on Social Network Sites (pp. 3958). New York and London: Routledge.

boyd, d. (2014). It's complicated: The social lives of networked teens. Yale University Press.

Caiani, M., \& Wagemann, C. (2009). Online networks of the Italian and German extreme right: An explorative study with social network analysis. Information, Communication \& Society, 12(1), 66-109.

Campbell, S. W. (2013) Mobile media and communication: A new field, or just a new journal?. Mobile Media \& Communication, 1(1), 8-13.

Chen, Y. Y., Bentley, F., Holz, C., \& Xu, C. (2015, August). Sharing (and discussing) the moment: The conversations that occur around shared mobile media. In Proceedings of the 17th International Conference on Human-Computer Interaction with Mobile Devices and Services (pp. 264-273). ACM

Cho, J., Gil De Zuñiga, H., Rojas, H., \& Shah, D. V. (2003). Beyond access: The digital divide and Internet uses and gratifications. It \& Society, 1, 46-72. 
Church, K., \& de Oliveira, R. (2013). What's up with Whatsapp? Comparing mobile instant messaging behaviors with traditional SMS. In Proceedings of the 15th international conference on Human-computer interaction with mobile devices and services (pp. 352-361). ACM.

Clark, L. S. (2016). Participants on the Margins: \#BlackLivesMatter and the Role That Shared Artifacts of Engagement Played Among Minoritized Political Newcomers on Snapchat, Facebook, and Twitter. International Journal of Communication, 10 (26).

Das, S., \& Kramer, A. D. (2013). Self-Censorship on Facebook. In Proceedings of the Seventh International AAAI Conference on Weblogs and Social Media (pp. 120-127). Washington, DC: AAAI.

Eliasoph, N. (1998). Avoiding politics: How Americans produce apathy in everyday life. Cambridge University Press.

Ellison, N., Steinfield, C., \& Lampe, C. (2007). The benefits of Facebook "friends": Exploring the relationship between college students' use of online social networks and social capital. Journal of Computer-Mediated Communication, 12(4), 1143-1168.

Ellison, N. B., Steinfield, C., \& Lampe, C. (2011). Connection strategies: Social capital implications of Facebook-enabled communication practices. New media \& society, 13(6), 873-892.

Gaines, B. J., \& Mondak, J. J. (2009). Typing together? Clustering of ideological types in online social networks. Journal of Information Technology \& Politics, 6(3-4), 216-231.

Gil de Zúñiga, H. \& Valenzuela, S. (2011). The mediating path to a stronger citizenship: Online and offline networks, weak ties, and civic engagement. Communication Research, 38(3), 397-421.

Goggin, G. (2009). Adapting the mobile phone: The iPhone and its consumption. Continuum: Journal of Media \& Cultural Studies, 23(2), 231-244. 
Hayes, A. F., Glynn, C. J., \& Shanahan, J. (2005). Willingness to self-censor: A construct and measurement tool for public opinion research. International Journal of Public Opinion Research, 17(3), 298-323.

Helles, R. (2013). Mobile communication and intermediality. Mobile Media \& Communication, 1(1), 14-19.

Hunt, J. (2006). Staunching emigration from East Germany: Age and the determinants of migration. Journal of the European Economic Association, 4(5), 10141037.

Jacob, M., \& Tyrell, M. (2010). The legacy of surveillance: An explanation for social capital erosion and the persistent economic disparity between East and West Germany. Available at SSRN 1554604.

Katz, E., Blumler, J. G., \& Gurevitch, M. (1973). Uses and gratifications research. Public Opinion Quarterly, 37(4), 509-523.

Martin, J. A. (2015). Mobile news use and participation in elections: A bridge for the democratic divide? Mobile Media \& Communication, 3(2), 230-249.

Marwick, A. E., \& boyd, d. (2011). I tweet honestly, I tweet passionately: Twitter users, context collapse, and the imagined audience. New Media \& Society, 13(1), 114-133.

MacKinnon, R. (2011). China's" networked authoritarianism". Journal of Democracy, 22(2), 32-46.

Min, S. J. (2010). From the digital divide to the democratic divide: Internet skills, political interest, and the second-level digital divide in political internet use. Journal of Information Technology \& Politics, 7(1), 22-35.

Neumayer, C., \& Stald, G. (2014). The mobile phone in street protest: Texting, tweeting, tracking, and tracing. Mobile Media \& Communication, 2(2), 117-133. 
Noelle-Neumann, E. (1974). The spiral of silence: A theory of public opinion. Journal of Communication, 24(2), 43-51.

Noelle-Neumann, E., (1984). The spiral of silence: Public opinion, our social skin. Chicago: University of Chicago Press.

O'Hara, K. P., Massimi, M., Harper, R., Rubens, S., \& Morris, J. (2014). Everyday dwelling with WhatsApp. In Proceedings of the 17th ACM conference on Computer supported cooperative work \& social computing (pp. 1131-1143). ACM.

Papacharissi, Z. (2011). Conclusion. A Networked Self. In A Networked Self. Identity, Community and Culture on Social Network Sites, Z. Papacharissi (ed.). New York and London: Routledge (pp. 304-317).

Pasek, J. (2016). When will nonprobability surveys mirror probability surveys? Considering types of inference and weighting strategies as criteria for Correspondence. International Journal of Public Opinion Research, 28(2), 269-291.

Quan-Haase, A., \& Young, A. L. (2010). Uses and gratifications of social media: A comparison of Facebook and instant messaging. Bulletin of Science, Technology \& Society, $30(5), 350-361$

Rainie, H., \& Wellman, B. (2012). Networked: The new social operating system. Cambridge, MA: Mit Press.

Sanders, D., Clarke, H. D., Stewart, M. C., \& Whiteley, P. (2007). Does mode matter for modeling political choice? Evidence from the 2005 British Election Study. Political Analysis, 15(3), 257-285.

Scheufele, D. A., \& Moy, P. (2000). Twenty-five years of the spiral of silence: A conceptual review and empirical outlook. International Journal of Public Opinion Research, 12(1), 3-28. 
Schudson, M. (1997). Why conversation is not the soul of democracy. Critical Studies in Media Communication, 14(4), 297-309.

Sleeper, M., Balebako, R., Das, S., McConahy, A. L., Wiese, J., \& Cranor, L. F. (2013). The post that wasn't: Exploring self-censorship on Facebook. In Proceedings of the 2013 conference on Computer supported cooperative work (pp. 793-802). ACM.

Song, F. W. (2010). Theorizing web 2.0: A cultural perspective. Information, Communication \& Society, 13(2), 249-275.

Utz, S., Muscanell, N., \& Khalid, C. (2015). Snapchat elicits more jealousy than Facebook: A comparison of Snapchat and Facebook use. Cyberpsychology, Behavior, and Social Networking, 18(3), 141-146.

Vaccari, C., Valeriani, A., Barberá, P., Jost, J. T., Nagler, J., \& Tucker, J. A. (2016). Of Echo Chambers and Contrarian Clubs: Exposure to Political Disagreement Among German and Italian Users of Twitter. Social Media + Society, DOI: $10.1177 / 2056305116664221$

Vaterlaus, J. M., Barnett, K., Roche, C., \& Young, J. A. (2016). “Snapchat is more personal": An exploratory study on Snapchat behaviors and young adult interpersonal relationships. Computers in Human Behavior, 62, 594-60.

Wellman, B. (2002). Little Boxes, Glocalization, and Networked Individualism. In M. Tanabe, P. van denBesselaar, \& T. Ishida (Eds.), Digital Cities II: Computational and Sociological Approaches (pp. 10-25), Berlin: Springer-Verlag.

Wojcieszak, M. (2010). 'Don't talk to me': Effects of ideologically homogeneous online groups and politically dissimilar offline ties on extremism. New Media \& Society, 12(4), 637-655. 